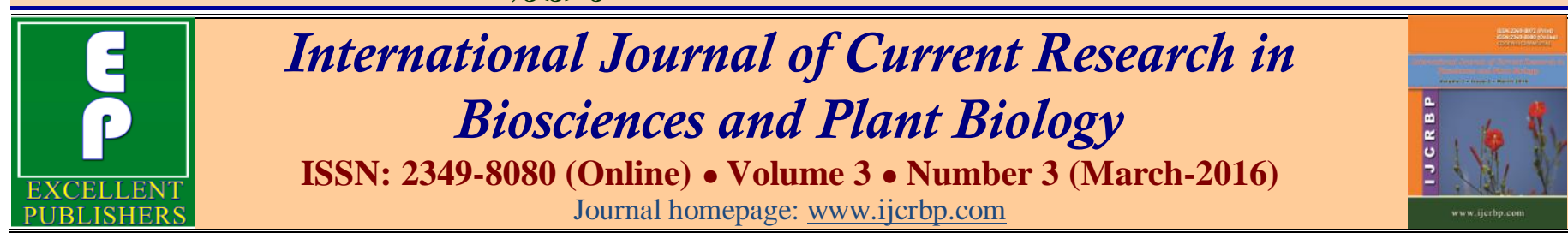

\title{
Ecofriendly Synthesis of Silver Nanoparticles from Eichhornia crassipes
}

\author{
Shokkanna Gounder Basker* \\ Department of Biotechnology, Nandha Arts and Science College, Erode- 638 o52, Tamil Nadu, India \\ *Present Address: Department of Botany, Government Arts and Science College (Autonomous), Salem-636 oo7, Tamil Nadu, \\ India
}

*Corresponding author.

\begin{abstract}
A b s t r act
A simple, non-toxic and eco-friendly technique was adopted for synthesizing silver nanoparticles (Ag NPs) by using aqueous leaf extracts of Eichhornia crassipes. In the present study, silver nanoparticles were synthesized using silver nitrate. The visual appearance of colour was noted and characterized further by UV, IR, SEM and XRD analysis. By using this green technique, silver nanoparticles can be effectively synthesized in a very short time which can be helpful in controlling its population.
\end{abstract}

\section{Article Info}

Accepted: 20 February 2016

Available Online: 06 March 2016

Ke ywords

Eichhornia crassipes

Silver nanoparticles

Weeds

\section{Introduction}

The revolution of nanotechnology has lifted to a new level of science, by adding new dimensions and novelty in the current scenario research. Nanoparticles exhibit various enhanced properties, distribution and morphological parameters than the conventional system of particles. The size of nanoparticles is 1- $100 \mathrm{~nm}$. Nanotechnology conceived with various basic aspects of science like physical, chemical and biological sciences. Biological method of synthesis of nanoparticles plays a significant importance in solving current day problems.

Nowadays, research on plants and plant resources are gaining much importance for their secondary metabolites. Nanoparticle production using plants can be useful for different purposes considering the ability to control the size and dispersion level of particles. The production of nanoparticles using plant extracts has been proved by many researchers (Nadagouda et al., 2009). Currently, synthesis of nanoparticles were performed using different noble metals like gold, silver, titanium, etc for their non-reactiveness and better stability and tolerance in different field of research. AgNPs have been synthesized using various plants like, Acalypha indica (Krishnaraj et al., 2010) Parthenium hysterophorus (Parashar et al., 2009), Aloe barbadensis (Chandran et al., 2006) and Gliricidia sepium (Rajesh et al., 2009). Control of weeds is a much challenging task for the researchers using different practices like physical, chemical and biological methods. Therefore to explore the possibilities of utilization of weeds by latest technology like nanoparticle synthesis can be adopted. The use of naturally available weeds for nanoparticle synthesis was performed by number of workers in weeds like Parthenium (Parashar et al., 2009), Hydrilla verticilata (Sable et al., 2012) Tinospora cordiofolia (Abbasi et al., 2014), Ipomea (Ganaie et al., 2014).

Eichhornia crassipes commonly known as Water hyacinth, a member of Pontederiaceae family (Pickere weed family) distributed widely in fresh water aquatic systems and considered as one of the worst weed in the world (Holm et al., 1991). Water Hyacinth remains a 
major problem in ponds, rivers, lakes and other stagnant water bodies if left uncontrolled. It contains numerous secondary metabolites and phytochemicals like phenalenone compounds alkaloids, flavonoids, phenols, sterols, terpenoids and anthoquinones (Lalitha et al., 2012). Hence, the present work was undertaken to utilize this aquatic weed for novel production of silver nanoparticles.

\section{Materials and methods}

\section{Collection and extraction}

Fresh plants of Eichhornia crassipes was collected from water bodies from different locations of Erode district, Tamil Nadu and the collected samples were pooled together. The collected plants were washed with tap water to remove the debris. The leaves were separated using a sharp blade and the fresh leaves were used for the experiment. About $25 \mathrm{~g}$ of fresh leaves were cut into small pieces and boiled in $80 \mathrm{ml}$ sterile distilled water for 30 minutes in a water bath to facilitate the formation of aqueous extracts. The aqueous extracts were filtered through Whatman No 1 filter paper. The volume of the filtrate was adjusted and made to $100 \mathrm{ml}$ by sterile distilled water. Silver nitrate (Hi Media), $1 \mathrm{mM}$ was prepared with sterile distilled water and homogenate thoroughly.

\section{Synthesis of silver nanoparticles}

About $1 \mathrm{mM}$ aqueous solution of silver nitrate was used for the synthesis of silver nanoparticles. The reaction medium contained $10 \mathrm{ml}$ of $E$. crassipes extracts and 90 $\mathrm{ml}$ of $1 \mathrm{mM}$ aqueous solution of silver nitrate. The bioreduction of colour was monitored and confirmed by using UV-Vis Spectra analysis. The spectroscopic studies were carried out using Systronics UV-Vis spectrophotometer. The synthesized silver nanoparticles were also analysed by scanning electron microscopy, FTIR Shimadzu and X-ray diffraction spectroscopy.

\section{Results and discussion}

Botanicals play an important role in synthesis of silver nanoparticles. The aquatic hydrophyte E. crassipes was capable of synthesizing silver metallic nanoparticle in the silver nitrate containing solution was revealed in the present study. As the plant extracts were added to aqueous silver nitrate solution, the colour gradually changed from light green to dark brown to reddish brown and finally to colloidal brown indicating silver nanoparticle formation
(Fig. 1). Silver metallic nanoparticles appear yellow brown in colour in aqueous solution as a result of surface plasmon vibrations (Krishnaraj et al., 2010). The transformation of colour is due to the chemical reduction of silver nitrate to silver as proven previously by many workers (Shukla et al., 2010; Singhal et al., 2011; Philip and Unni 2011;Namratha and Monica 2013; Lalitha et al., 2013). The confirmation of silver nanoparticle synthesis was performed further by UV visible Spectrophotometer from the initiation of reaction to the change of colour of the solution. UV-vis spectrograph of the colloidal solution of Ag NPs has been recorded as a function of time (Fig. 2 ). The conversion of silver nanoparticles at 4 hours of time was maximum with $450 \mathrm{~nm}$, later the conversion of nanoparticles was decreased gradually at $23 \mathrm{hrs}$. The process is mainly due to surface plasmon resonance of silver nanoparticles. Broadening of the peak which indicated the formation of polydispersed large nanoparticles due to slow reduction rates (Singhal et al., 2011; Philip and Unni, 2011). The time taken for the synthesis of silver nanoparticles was initiated in the present study was about 25 minutes and finally the reaction stopped after $23 \mathrm{hrs}$. The presence of phytochemicals of the plant extracts may involve in the reduction of silver nitrate to silver metallic ions.

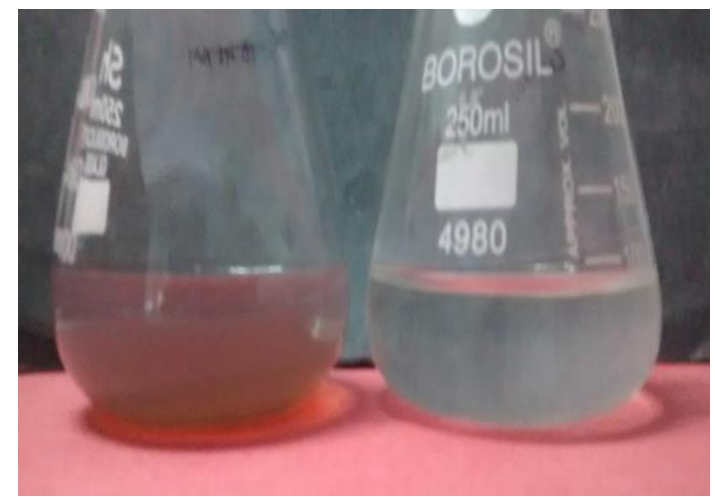

Fig. 1: Change in colour of the solution with silver nanoparticles and no colour in control.

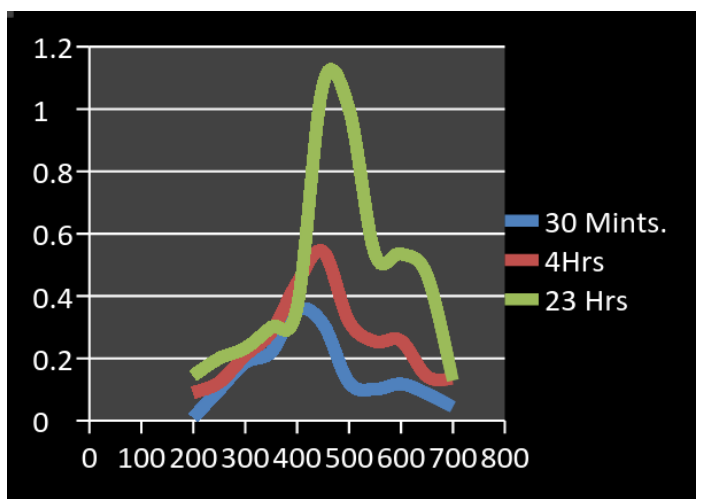

Fig. 2: UV Absorption of E. crassipes silver nanoparticles. 
FT-IR technique is a useful analytical method for the identification of surface groups. FT-IR transmission spectrum was used to investigate variations in the functional groups of the synthesized silver nanoparticle used in the experiments. In the present investigation, silver nanoparticle exhibited $\mathrm{O}-\mathrm{H}$ and $\mathrm{N}-\mathrm{H}$ stretching in between $3281.02-3539.49 \mathrm{~cm}^{-1}$ (Fig. 3). The peak at $3448.84 \mathrm{~cm}^{-1}$ is assigned to $\mathrm{O}-\mathrm{H}$ broadening stretching peak. Band around $3000 \mathrm{~cm}^{-1}$ indicating the presence of the unsaturated alkynes $\mathrm{C}=\mathrm{C}$ stretching modes. The absorption band between 1741.78-1795.97 $\mathrm{cm}^{-1}$ indicates the anhydride $\mathrm{C}=\mathrm{O}$ bond. Peak appears at $1647.26 \mathrm{~cm}^{-1}$ reveals that the bending vibration of amide (Vanmathi Selvi and Sivakumar, 2012). The band at $1419.66 \mathrm{~cm}^{-1}$ is associated with C-H Symmetric bending (Suarez-Garcia et al., 2002). Bands in the range of 1022.31 to $1269.20 \mathrm{~cm}^{-1}$ includes $\mathrm{C}-\mathrm{O}$ in Carboxylic acids, alcohols, esters and $\mathrm{P}=\mathrm{O}$ bond in phosphate esters (Deng et al., 2010). The region in between $700-900 \mathrm{~cm}^{-1}$ contains various bands related to aromatic, out of plane $\mathrm{C}-\mathrm{H}$ bending with different degrees of substitution. The peaks around 626.89 to $675.11 \mathrm{~cm}^{-1}$ confirmed vibration of $\mathrm{C}-\mathrm{H}$ bending mode (Venkatachalam et al., 2012). Some weak bands were also observed in the range of $657.11-462.93 \mathrm{~cm}^{-1}$, indicates $\mathrm{C}-\mathrm{C}$ stretching.

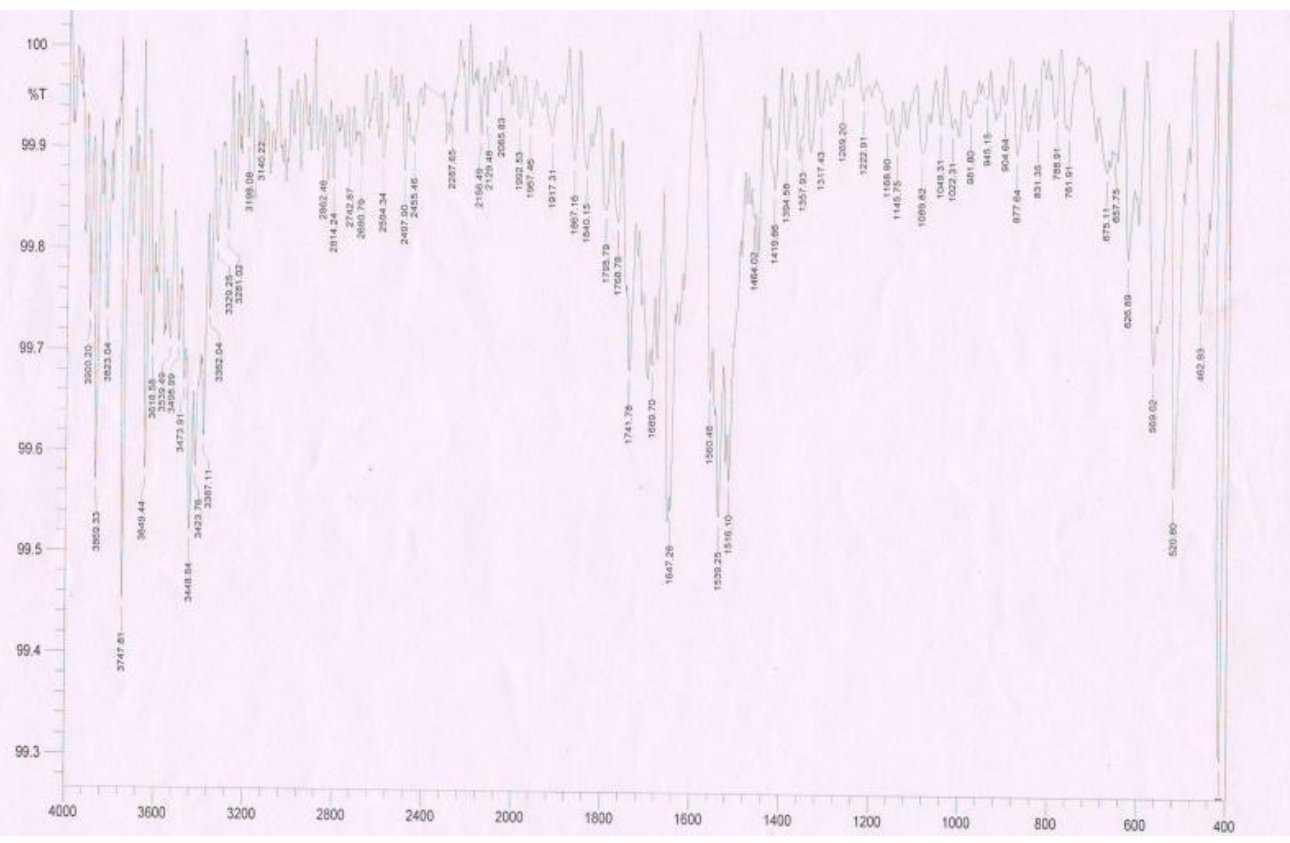

Fig. 3: FT-IR spectra of silver nanoparticles from $E$. crassipes.

The silver nanoparticles were subjected for the SEM analysis in which the details of magnification, voltage and scale were imprinted in the micrograph itself. The Fig. 4 indicated that the shape of silver nanoparticles synthesized at room temperature was found to show mixed group made of spherical, rhomboid, rectangular, triangular and square shaped particles. Similar type of distinct shapes within a single group was reported on gold nanoparticles synthesized using algae (Parial et al., 2012) and silver nanoparticles synthesized using Annona reticulata (Shivakumar Singh and Vidyasagar, 2014). The difference in the morphology of the nanoparticle synthesized may be the possible reason for the difference in optical properties (Xu and Käll, 2002). The images of Fig. 5 had confirmed the agglomerated nature of the particles which might be due to difference in preparative condition (Dheeban Shankar et al., 2014) and lack of stabilizing agent. The polymorphic gold nanoparticles synthesis was reported from Citrus limon, Murraya koenigii Linn. leaves, and Canna indica (red) and Quisqualis indica pink flowers. The gold nanoparticles were polymorphic, stable, size $30-130 \mathrm{~nm}$ in non agglomerated form (Shukla and Vankar, 2012). Lonicera japonica plant leaf extract was investigated for the synthesis of silver and gold nanoparticles. The particles were different in size and shape; silver nanoparticles were $36-72 \mathrm{~nm}$ in size and their shape was spherical to plate-like poly-shaped, while gold nanoparticles synthesized were poly-shaped nanoplates of $40-92 \mathrm{~nm}$ in size. The molecules involved in the synthesis and capping of silver and gold nanoparticles were reported as carbohydrates, polyphenols, and protein (Kumar and Yadav, 2011). The results of the earlier study coincide with the results of the present study. 


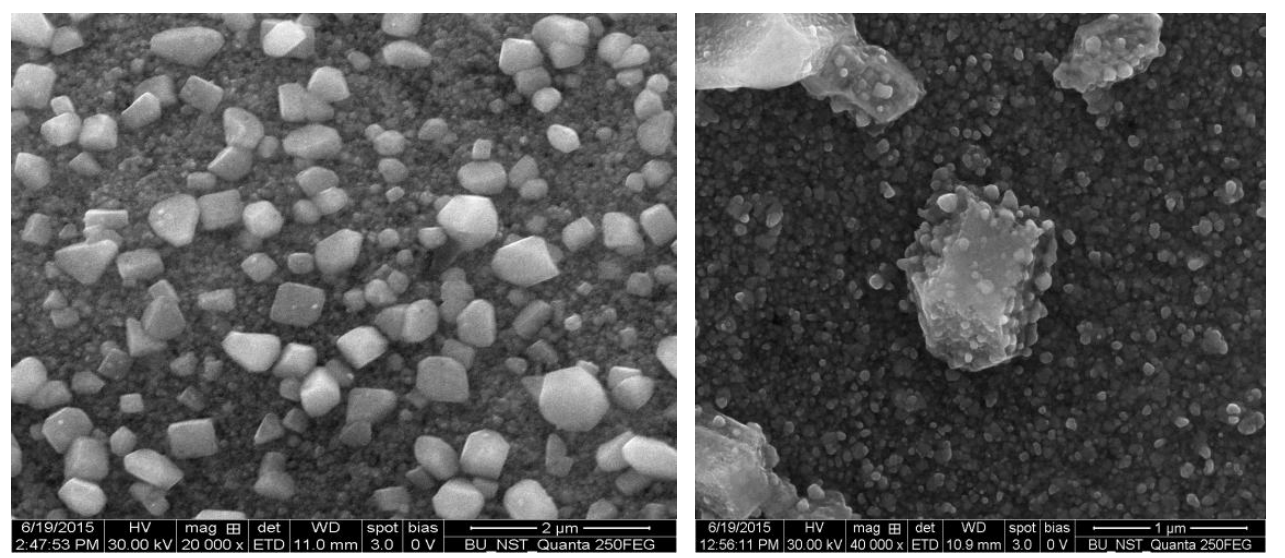

Fig. 4 and Fig. 5: SEM analysis of silver nanoparticles produced by E. crassipes showing polymorphism and agglomeration.

EDAX analysis gives qualitative as well as quantitative status of elements that involved in formation of nanoparticles which confirmed the reduction of silver ions into elements of silver and showed the presence of elemental silver as the major constituent. The presence of elemental silver can be observed in the graph obtained from EDAX analysis which confirmed the elemental constituents of silver (69.01\%), chloride (15.44\%),

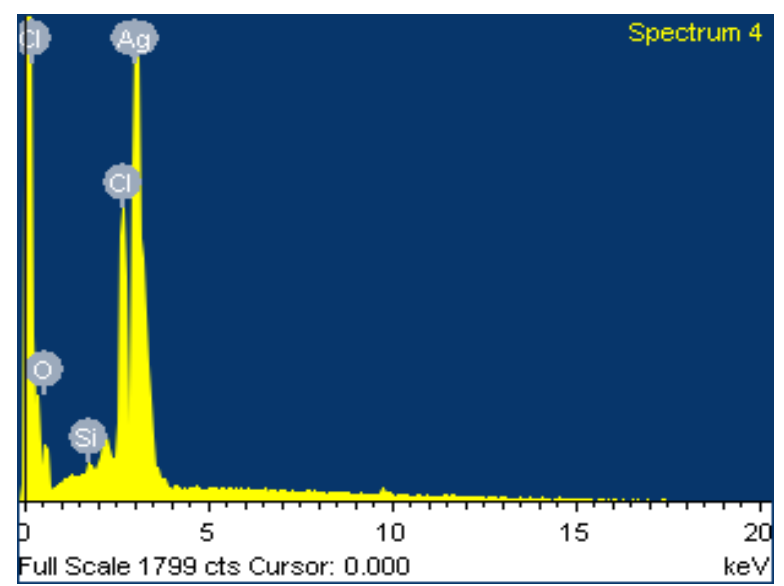

Fig. 6: EDAX of silver nanoparticles of E. crassipes.

The structure of the phytosynthesized silver nanoparticles was also investigated by XRD. Fig. 7 depicts the XRD pattern for silver nanoparticles produced from E. crassipes leaf extracts. XRD profile had revealed three distinct diffraction peaks at $32.1^{\circ}$ $38.1^{\circ}$ and $46.2^{\circ}$ which could be indexed $2 \theta$ values of (200), (111) and (311) respectively and indicated the reflections of metallic silver with crystalline phase. The average grain size of the silver nanoparticles formed in the bioreduction process was determined using Scherrer's formula and was estimated to be $\sim 6.69 \mathrm{~nm}$ to $9.8 \mathrm{~nm}$. In the present investigation, silver nanoparticles were synthesized effectively using the leaf extracts of silicon $(0.72 \%)$ and oxides (14.83\%) respectively (Fig. $6)$. The most principal sharp signal was observed at 3 $\mathrm{keV}$ for silver, which is found to be a distinctive for the absorption of crystalline nature of biosynthesized silver nanoparticles (Muthukrishnan et al., 2015; Kanipandian et al., 2014; Ramalingam et al., 2014). These results were found to be supported by the reports of Bhakya et al. (2015).

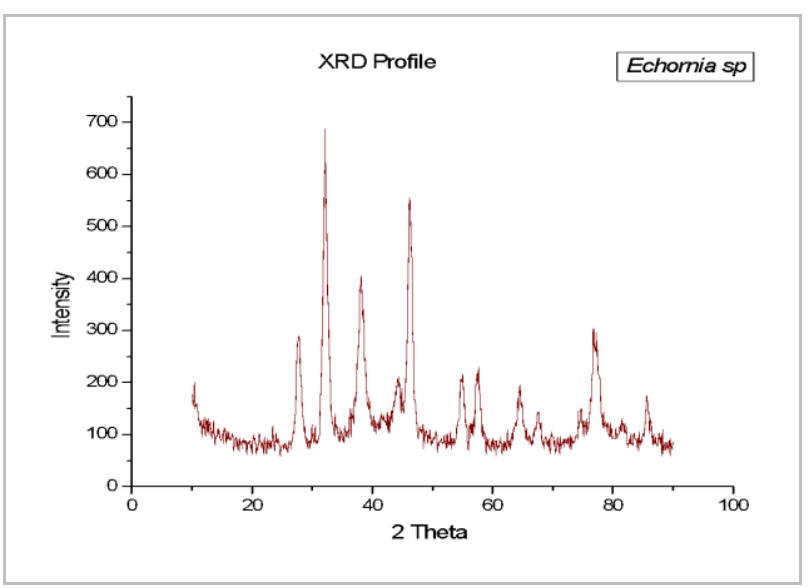

Fig. 7: XRD data of silver nanoparticles of E. crassipes.

Eichhornia crassipes. The results obtained showed the potentiality of the weed for biostabilized silver nanoparticle synthesis in a green manner.

\section{Conflict of interest statement}

Authors declare that they have no conflict of interest.

\section{Acknowledgement}

The author would like to express his sincere thanks to UGC-SERO, Hyderabad for the financial assistance (Ref. MRP 5059/14). 


\section{References}

Abbasi, T., Anuradha, J., Abbasi, S. A., 2014. Utilization of the terrestrial weed Guduchi (Tinospora cordifolia). Nano Sci. Technol. 1(3), 1-7.

Bhakya, S., Muthukrishnan, S., Sukumaran, M., Muthukumar, M., 2015. Biogenic synthesis of silver nanoparticles and their antioxidant and antibacterial activity. Appl. Nano Sci. 1-12.

Chandran, S.P., Chaudhary, M., Pasricha, R., Ahmad, A., Sastry, M., 2006. Synthesis of gold nanotriangles and silver nanoparticles using Aloe vera plant extract. Biotechnol. Prog. 22, 577-583.

Deng, H., Zhang, G., Xv, X. Tao,G., Dai, J., 2010. Optimization of preparation of activated carbon from cotton stalk by microwave assisted phosphoric acid chemical activation. J. Hazard. Mater. 182, 217-224.

Dheeban Shankar, P., Ananthi, P., Nirupama Devi, K.H., 2014. Bioinspired Synthesis and Characterization of Silver Nanoparticles using an Aqueous extract of Artabotrys hexapetalus. J. Nano Sci. Nanotechnol. 2(1), 66-70.

Ganaie, S.U., Abbasi, T., Anuradha, J., Abbasi, S. A., 2014. Biomimetic synthesis of silver nanoparticles using the amphibious weed Ipomoea and their application in pollution control. J. King Saud Univ. Sci. 26, 222-229.

Holm, L.G., Plucknett, D.L., Pancho, J.V., Herberger, J.P., 1991. The World's Worst Weed: Distribution and Biology. Krieger Publishing Co., Malabar, Fla USA.

Kanipandian, N., Kannan, S., Ramesh, R., Subramanian, P., Thirumurugan, R., 2014. Characterization, antioxidant and cytotoxicity evaluation of green synthesized silver nanoparticles using Cleistanthus collinus extract as surface modifier. Mater. Res. Bull. 49, 494-502.

Krishnaraj, C., Jagan, E.G., Rajasekar, S., Selvakumar, P., Kalaichelvan, P.T., Mohan, N., 2010. Synthesis of silver nanoparticles using Acalypha indica leaf extracts and its antibacterial activity against water borne pathogens. Colloids Surf. B: Biointerfaces. 76, 50-56.

Kumar, V., Yadav, S.K., 2011. Synthesis of stable, polyshaped silver and gold nanoparticles using leaf extract of Lonicera japonica L. Int. J. Green Nanotechnol. 3(4), 281-291.

Lalitha, A., Subbaiya, R., Ponmurugan, P., 2013. Green synthesis of silver nanoparticles from leaf extract Azhadirachta indica and to study its anti-bacterial and antioxidant property. Int. J. Curr. Microbiol. App. Sci. 2, $228-235$.

Lalitha, P., Sripathi, S., Jayanthi, P., 2012. Secondary metabolites of Eichhornia crassipes (Water hyacinth): A review (1949 to 2011). Nat. Prod. Commun. 7, 12491256.

Muthukrishnan, S., Bhakya, S., Kumar, T.S., Rao, M.V., 2015. Biosynthesis, characterization and antibacterial effect of plant-mediated silver nanoparticles using
Ceropegia thwaitesii-An endemic species. Ind. Crops Prod. 63, 119-124.

Nadagouda, M.N., Hoag, G., Collins, J., Varma, R.S., 2009. Green synthesis of $\mathrm{Au}$ nanostructures at room temperature using biodegradable plant surfactants. J. Cryst. Growth Des. 9, 4979-4983.

Namratha, N., Monica, P.V., 2013. Synthesis of silver nanoparticles using Azadirachta indica (Neem) extract and usage in water purification. Asian J. Pharm. Tech. 3, 170-174.

Parashar, V., Parashar, R., Sharma, B., Pandey, A.C., 2009. Parthenium leaf extract mediated synthesis of silver nanoparticles: a novel approach towards weed utilization. Digest. J. Nanomater. Biostruct. 4, 45-50.

Parial, D., Patra, H. K., Dasgupta, A. K. R., Pal, R., 2012. Screening of different algae for green synthesis of gold nanoparticles. Eur. J. Phycol. 47(1), 22-29.

Philip, D., Unni, C., 2011. Extra cellular biosynthesis of gold and silver nanoparticles using Krishna tulsi (Ocimum sanctum) leaf. Phys. E. 43, 1318-1322.

Rajesh, W.R., Lakkakula jaya, R., Kolekar Niranjan, S., Mendhulkar Vijay, D., Kashid Sahebree, B., 2009. Phytosynthesis of silver nanoparticle using Gliricidia sepium (Jacq.). Curr. Nanosci. 5, 117-122.

Ramalingam, V., Rajaram, R., Premkumar, C., Santhanam, C., Dhinesh, P., Vinothkumar, S., Kaleshkumar, K., 2014. Biosynthesis of silver nanoparticles from deepsea bacterium Pseudomonas aeruginosa JQ989348 for antimicrobial, antibiofilm and cytotoxic activity. J. Basic Microbiol. 54, 928-936.

Sable, N., Gaikwad, S., Bonde, S., Gade, A., Rai, M., 2012. Phytofabrication of silver nanoparticles by using aquatic plant Hydrilla verticilata. Biosci. 4(2), 45-49.

Shivakumar Singh, P., Vidyasagar, G.M., 2014. Biosynthesis, characterization and antidermatophytic activity of silver nanoparticles using Raamphal plant (Annona reticulata) aqueous leaves extract. Ind. J. Materials Sci. 2014(2014), Article ID 412452. 5p.

Shukla, D., Vankar, P.S., 2012. Synthesis of plant parts mediated gold nanoparticles, Int. J. Green Nanotechnol. 4(3), 277-288.

Shukla, V.K., Pandey, S., Pandey, A.C., 2010. Green synthesis of silver nanoparticles using neem leaf (Azadirachta indica) extract. In: Proc. Int. Conf. Adv. Nanomater. Nanotechnol. ICANN-2009, Guwahati, Assam (India). pp.9-11.

Singhal, G., Bhavesh, R., Kasariya, K., Sharma, A.R., Singh, R.P., 2011. Biosynthesis of silver nanoparticles using Ocimum sanctum (Tulsi) leaf extract and screening its antimicrobial activity. J. Nanoparticle Res. 13, 29812988.

Suarez-Garcia, F., Martinez-Alonso, Tascon, J.M.D., 2002. A comparitive study of the thermal decomposition of apple pulp in the absence and presence of phosphoric acid. Polymer Degrad. Stability. 75, 375-383. 
Vanmathi Selvi, K., Sivakumar, T., 2012. Isolation and characterization of silver nanoparticles from Fusarium oxysporum. Int. J. Curr. Microbiol. Appl. Sci. 1(1), 56-62.

Venkatachalam, K., Visuvamithiran, P., Sundaravel, B., Palanichamy, M., Murugesan, V., 2012. Catalytic performance of Al-MCM-48 molecular sieves for isopropylation of phenol with isopropyl acetate, Chinese J. Catal. 33(2-3), 478-486.

$\mathrm{Xu}$, H., Kall, M., 2002. Morphology effects on the optical properties of silver nanoparticles. J. Nanosci. Nanotechnol. 4, 254-259.

\section{How to cite this article:}

Basker, S., 2016. Ecofriendly synthesis of silver nanoparticles from Eichhornia crassipes. Int. J. Curr. Res. Biosci. Plant Biol. 3(3), 56-61. doi: http://dx.doi.org/10.20546/ijcrbp.2016.303.011 